Review

\title{
The Dynamics of Norovirus Outbreak Epidemics: Recent Insights
}

\author{
John A. Marshall * and Leesa D. Bruggink \\ Victorian Infectious Diseases Reference Laboratory, 10 Wreckyn Street, North Melbourne, \\ Victoria 3051, Australia; E-Mail: leesa.bruggink@mh.org.au \\ * Author to whom correspondence should be addressed; E-Mail: john.marshall@ mh.org.au; \\ Tel.: +61-3-9342-2678; Fax: +61-3-9342-2660.
}

Received: 23 February 2011; in revised form: 11 April 2011 / Accepted: 13 April 2011 /

Published: 15 April 2011

\begin{abstract}
Noroviruses are a major cause of gastroenteritis outbreaks worldwide. Norovirus outbreaks frequently occur as epidemics which appear to be related to both genetic and environmental factors. This review considers recent progress in understanding these factors. The norovirus genome undergoes continuous change and this appears to be important in the persistence of the virus in the community. Studies on the common GII.4 genotype have shown that some norovirus outbreak epidemics involving this genotype are correlated with specific changes in the genome. In contrast to the growing understanding of the role of genetic factors in norovirus outbreak epidemics, the role of environmental factors is less well understood. Topics reviewed here include long term excretion of norovirus in some individuals, long term survivability of norovirus in the environment, the role of meteorological factors in the control of norovirus outbreaks and the possible zoonotic transmission of the virus.
\end{abstract}

Keywords: norovirus; outbreaks; epidemics; genetic factors; environmental factors

\section{Introduction}

The noroviruses, which are single-stranded positive sense RNA viruses classified in the genus Norovirus within the family Caliciviridae [1], are now considered the most common cause of outbreaks of non-bacterial gastroenteritis worldwide [1], as well as being an important cause of 
sporadic gastroenteritis [1]. Epidemics of norovirus outbreaks, which can be defined as peaks in the incidence of outbreaks above the general level [2,3], are well established [3-5]. Norovirus outbreak epidemics can show an annual cyclic periodicity [3-5] and the dynamics of norovirus outbreak epidemics appear to be dependent on a complex interaction of different variables which include both genetic and environmental factors [4].

This review examines recent progress in understanding the roles of genetic and environmental factors in the control of the incidence of norovirus outbreak epidemics. The term "genetic" refers principally to nucleotide changes in the norovirus genome. Two main topics are reviewed here. Firstly, general aspects of genetic change in the norovirus genome and their relationship to altered infectivity/virulence of the virus are considered. Secondly, numerous recent studies linking genetic changes in the GII.4 genotype to changes in the pattern of outbreak epidemics linked to this genotype are reviewed. Topics reviewed in the category of "environmental factors" include norovirus excretion patterns, norovirus survivability in the environment, the role of meteorological factors in the control of norovirus outbreak epidemics and the possible zoonotic transmission of norovirus.

\section{Genetic Factors}

\subsection{General}

The norovirus genome is approximately $7.6 \mathrm{~kb}$ in length and typically comprises three open reading frames (ORFs) [1]. ORF 1 encodes the non-structural polyprotein, ORF 2 encodes the major structural capsid protein and ORF 3 encodes a small virion-associated protein [1]. Recent studies indicate that murine norovirus has an additional ORF, ORF 4, which overlaps ORF 2 [6].

Noroviruses are currently classified into five genogroups [7,8]. Three of these, genogroups I, II and IV (GI, GII and GIV), occur in human infections [9,10] though most noroviruses affecting humans belong to GI or GII [11]. Within each genogroup one or more "clusters" or "genotypes" have been identified [7,9,10]. In a major review of norovirus classification, Zheng et al. [7] examined 164 amino acid sequences from the capsid region of both human and animal noroviruses. These authors identified five genogroups comprising 29 genotypes, with eight genotypes in GI, 17 in GII, two in GIII, and one each in GIV and GV. More recently, Patel et al. [8] identified 32 genotypes among the five genogroups.

The major capsid protein encoded by ORF 2, which is referred to as VP1, is of considerable interest because it is believed to be involved in the recognition of the host receptor [12,13]. VP1 includes a shell and a protruding (P) domain, which, in turn, is made up of P1 and P2 subunits [10]. The P2 subunit is considered critical for receptor binding [10,12]. It has been proposed that amino acid changes in the P2 domain allow the virus to reinfect an individual (e.g., by host cell receptor switching) and thereby escape herd immunity [14].

The norovirus genome undergoes frequent change [15,16] by mechanisms including mutation [17] and recombination [18]. Although the relative importance of mutation vs. recombination in the evolution of norovirus remains unclear [19], there appears to be no doubt that recombination is important. For example, Bull et al. [18] identified 20 norovirus recombinant types in circulation 
worldwide and Motomura et al. [20] have suggested that recombination could be an important mechanism by which GII.4 remains persistent in human populations.

There is now some evidence that a small genetic change in the capsid region can have a big influence on norovirus virulence. Bailey et al. [21] found that murine norovirus virulence was linked to a glutamate to lysine substitution in the capsid region. Various nucleotide changes in other parts of the genome have also been linked to changes in norovirus virulence. For example, there is some evidence that nucleotide changes in the polymerase region of human GII.4 noroviruses may influence virulence [22-24].

\subsection{Studies on GII.4 Variants}

GII.4 norovirus is the most common cause of human norovirus outbreaks worldwide [25] and GII.4 noroviruses have been the focus of much genetic research. GII.4 strains frequently undergo genetic change and these altered forms are sometimes termed "variants" [25-27] or "subtypes" [20]. There is some evidence that the emergence of new GII.4 variants can correlate with the occurrence of norovirus outbreak epidemics. For example, the appearance of the GII.4 "Hunter" variant in Australia in 2004 coincided with an increase in norovirus outbreak activity [25]. Kroneman et al. [28] reported that an increase in gastroenteritis outbreaks in the Netherlands in 2004 was linked to the appearance of the GII.4 “GII.4-2004” variant. Ho et al. [29] reported a norovirus outbreak epidemic in 2006 in Hong Kong was linked to the emergence of the GII.4 "95/96-like" variant.

Variants have been identified as a cluster in either the GII.4 ORF 1 phylogenetic tree [3] or in the GII.4 ORF 2 phylogenetic tree [25]. In a study spanning 2002 to 2007 Bruggink and Marshall [3] found that each GII.4 norovirus outbreak epidemic was linked to one of four variants identified and there was a time link, a delay of 2 to 6 months, between the first detection of a GII.4 variant and the first outbreak epidemic in which it was the principal variant. It should be noted that the same GII.4 variant could be the principal variant in norovirus outbreak epidemics in successive years, so that the appearance of new variants cannot explain the annual cycle of GII.4 norovirus outbreak epidemics, thereby suggesting that environmental factors are important in the initiation of an epidemic (see Section 3.4).

\section{Environmental Factors}

\subsection{General}

Noroviruses can be spread by contaminated food or water, person-to-person contact [10] or aerosols [30,31]. Noroviruses are usually detected in faeces but have also been detected in vomitus [10] but apparently not in nasopharyngeal washings [10]. Norovirus-associated gastroenteritis outbreaks can occur in virtually any situation where groups of individuals gather together, including child-minding centres, school outings, camps, restaurants, hospitals, hostels, nursing homes, prisons and cruise ships $[10,32,33]$. The mode of spread of norovirus, its ubiquitous nature and the regular periodicity of norovirus outbreak epidemics [3-5] suggest environmental factors are important in the spread of the virus and some key topics here are considered next. 


\subsection{Norovirus Excretion Patterns}

Norovirus excretion patterns may play an important role in the spread of the virus. Some key findings follow. There is now evidence that norovirus RNA or virion excretion can occur in the absence of major symptoms of gastroenteritis. For example, norovirus RNA or virion excretion can occur after major symptoms have abated [34-36] and there is a report in which norovirus RNA excretion was found in an individual the day before the onset of symptoms [36]. Furthermore, volunteer studies indicate that norovirus can be detected in infected individuals with no major symptoms [37] but studies of the asymptomatic excretion of norovirus RNA in naturally infected individuals indicate the percentage of asymptomatic excretors appears to depend on the population being sampled [38-40]. Norovirus excretion can continue for long periods. Norovirus has been detected up to seven days after inoculation of virus in one volunteer study [37] and norovirus RNA for up to 44.5 days following onset of symptoms in a naturally infected individual [41]. Prolonged norovirus RNA excretion is well documented in immunocompromised individuals [42-44].

\subsection{Norovirus Survivability in the Environment}

A number of studies have examined norovirus survivability in the environment. As human norovirus cannot be grown reliably in culture [45], a variety of approaches have been tried including the use of cultivable norovirus surrogates $[46,47]$ or the application of a human norovirus "infectivity assay", which does not involve a culture system [48]. Taken together all the approaches used indicate norovirus can survive for long periods in the environment. A brief review of some key studies follows.

Doultree et al. [46] used feline calicivirus as a norovirus surrogate in studies on the survivability of the virus in a variety of conditions. These authors found that the virus survived for at least 60 days at $4{ }^{\circ} \mathrm{C}$ with minimal loss of infectivity. At room temperature feline calicivirus was stable for 14 to 21 days in suspension in culture medium and 21 to 28 days in the dried state.

Bae and Schwab [47] compared the survivability of feline calicivirus with that of murine norovirus in water and concluded that murine norovirus had significantly higher rates of survivability than those of feline calicivirus. In particular, infectivity reduction at $25{ }^{\circ} \mathrm{C}$ was greater for feline calicivirus $\left(0.18 \log _{10} /\right.$ day $)$ than for murine norovirus $\left(0.09 \log _{10} /\right.$ day $)$. Similarly, nucleic acid reduction rates at $25{ }^{\circ} \mathrm{C}$, determined using a multiple linear regression model, were higher for feline calicivirus $\left(0.08 \pm 0.03 \log _{10} /\right.$ day $)$ than for murine norovirus $\left(0.04 \pm 0.03 \log _{10} /\right.$ day $)$. However, caution is needed in assuming murine norovirus is the ideal surrogate for human norovirus in such studies. Tan and Jiang [13] and Lay et al. [49], for example, note that there appear to be important differences between human and murine noroviruses. These differences include the areas of clinical manifestation, host receptors, range of cell types where replication occurs and pathogenesis.

Lamhoujeb et al. [48] used human norovirus to study the survivability of norovirus on "food-contact" surfaces such as stainless steel and polyvinyl chloride. In their study, the identification of putatively infectious and noninfectious norovirus was based on an assay which utilized enzymatic pre-treatment of the virus such that noninfectious virus was believed to have been removed. On this basis the authors concluded that human norovirus could remain infectious for up to 28 days on both surface types at $20^{\circ} \mathrm{C}$. 


\subsection{Meteorological Factors}

Currently there is little understanding of what environmental factors may correlate with the annual cycle of norovirus outbreak epidemics, but there is now some information on temperature and rainfall. Current evidence indicates temperature is not one of these factors, as norovirus outbreak epidemics tend to occur in colder months of the year in the northern hemisphere [50] and warmer months of the year in the southern hemisphere [4,32]. On the other hand there is evidence noroviruses can be spread by waterborne methods [51,52], thereby suggesting rainfall may be able to play a role in the control of norovirus outbreaks. Recent evidence supports this hypothesis. Bruggink and Marshall [53] found there was a statistically significant correlation between monthly norovirus outbreak incidence and average rainfall in a 2002-2007 study in Australia. It was found there was a lag of about three months between peak average rainfall and a norovirus outbreak epidemic following in the same calendar year. These results suggest that there is an environmental reservoir for norovirus and that rain, perhaps by altering the turbidity of reservoirs of water-borne norovirus, stimulates the spread of norovirus in the community and thereby helps initiate an outbreak epidemic.

\subsection{Zoonotic Transmission of Norovirus?}

Norovirus has been detected in a variety of animals including pigs [12,54,55], cattle [12], mice [12,56], dogs [57-60], sheep [55] and a lion [61]. The genogroups associated with human and animal noroviruses are as follows. GI norovirus has been linked to humans [57], GII norovirus to humans [57], pigs [57] and cattle [62], GIII norovirus to cattle [12,57,62] and sheep [55], GIV norovirus to humans [57], a lion [61] and dogs [57,60] and GV norovirus to mice [57]. It has been suggested that there is at least one additional norovirus genogroup, and that viruses in this group occur in dogs and humans [58,59].

A key public health question in this area is whether animals can act as a reservoir for human noroviruses. In a review of the literature, Koopmans [45] noted that, although zoonotic transmission of noroviruses had not been observed, the current understanding of norovirus epidemiology was too limited to be sure this did not occur.

\section{Conclusions}

It is now established that the norovirus genome undergoes frequent change and there is evidence that some of these changes are linked to altered viral infectivity. However, there is also evidence that environmental factors are important in the spread of norovirus. Future studies should not neglect the potential importance of environmental factors in developing a full understanding of the dynamics of norovirus outbreak epidemics.

\section{References}

1. Marshall, J.A.; Bruggink, L.D. Laboratory diagnosis of norovirus. Clin. Lab. 2006, 52, 571-581.

2. Friedman, G.D. Primer of Epidemiology, 5th ed.; McGraw-Hill: New York, NY, USA, 2004; p. 79.

3. Bruggink, L.D.; Marshall, J.A. Molecular changes associated with altered patterns of norovirus outbreak epidemics in Victoria, Australia, in 2006 to 2007. J. Clin. Microbiol. 2010, 48, 857-861. 
4. Bruggink, L.D.; Marshall, J.A. Norovirus epidemics are linked to two distinct sets of controlling factors. Int. J. Infect. Dis. 2009, 13, e125-e126.

5. Siebenga, J.J.; Vennema, H.; Zheng, D.P.; Vinje, J.; Lee, B.E.; Pang, X.L.; Ho, E.C.M.; Lim, W.; Choudekar, A.; Broor, S.; et al. Norovirus illness is a global problem: emergence and spread of norovirus GII.4 variants, 2001-2007. J. Infect. Dis. 2009, 200, 802-812.

6. Thackray, L.B.; Wobus, C.E.; Chachu, K.A.; Liu, B.; Alegre, E.R.; Henderson, K.S.; Kelley, S.T.; Virgin, H.W. Murine noroviruses comprising a single genogroup exhibit biological diversity despite limited sequence divergence. J. Virol. 2007, 81, 10460-10473.

7. Zheng, D.P.; Ando, T.; Fankhauser, R.L.; Beard, R.S.; Glass, R.I.; Monroe, S.S. Norovirus classification and proposed strain nomenclature. Virology 2006, 346, 312-323.

8. Patel, M.M.; Hall, A.J.; Vinje, J.; Parashar, U.D. Noroviruses: A comprehensive review. J. Clin. Virol. 2009, 44, 1-8.

9. Vinje, J.; Hamidjaja, R.A.; Sobsey, M.D. Development and application of a capsid VP1 (region D) based reverse transcription PCR assay for genotyping of genogroup I and II noroviruses. J. Virol. Methods 2004, 116, 109-117.

10. Green, K.Y. Caliciviridae: The noroviruses. In Fields Virology, 5th ed.; Knipe, D.M., Howley, P.M., Eds.; Wolters Kluwer/Lippincott Williams \& Wilkins: Philadelphia, PA, USA, 2007; Volume 1, Chapter 28, pp. 949-979.

11. Burton-MacLeod, J.A.; Kane, E.M.; Beard, R.S.; Hadley, L.A.; Glass, R.I.; Ando, T. Evaluation and comparison of two commercial enzyme-linked immunosorbent assay kits for detection of antigenically diverse human noroviruses in stool samples. J. Clin. Microbiol. 2004, 42, 2587-2595.

12. Scipioni, A.; Mauroy, A.; Vinje, J.; Thiry, E. Animal noroviruses. Vet. J. 2008, 178, 32-45.

13. Tan, M.; Jiang, X. Norovirus gastroenteritis, carbohydrate receptors, and animal models. PLoS Pathogens 2010, 6, e1000983.

14. Donaldson, E.F.; Lindesmith, L.C.; Lobue, A.D.; Baric, R.S. Norovirus pathogenesis: Mechanisms of persistence and immune evasion in human populations. Immunol. Rev. 2008, 225, 190-211.

15. Bok, K.; Abente, E.J.; Realpe-Quintero, M.; Mitra, T.; Sosnovtsev, S.V.; Kapikian, A.Z.; Green, K.Y. Evolutionary dynamics of GII.4 noroviruses over a 34-year period. J. Virol. 2009, 83, 11890-11901.

16. Siebenga, J.J.; Lemey, P.; Kosakovsky Pond, S.L.; Rambout, A.; Vennema, H.; Koopmans, M. Phylodynamic reconstruction reveals norovirus GII.4 epidemic expansions and their molecular determinants. PLoS Pathogens 2010, 6, e1000884.

17. Dingle, K.E.; Norovirus Infection Control in Oxfordshire Communities Hospitals. Mutation in a Lordsdale norovirus epidemic strain as a potential indicator of transmission routes. J. Clin. Microbiol. 2004, 42, 3950-3957.

18. Bull, R.A.; Tanaka, M.M.; White, P.A. Norovirus recombination. J. Gen. Virol. 2007, 88, 3347-3359.

19. Rohayem, J.; Munch, J.; Rethwilm, A. Evidence of recombination in the norovirus capsid gene. J. Virol. 2005, 79, 4977-4990.

20. Motomura, K.; Yokoyama, M.; Ode, H.; Nakamura, H.; Mori, H.; Kanda, T.; Oka, T.; Katayama, K.; Noda, M.; Tanaka, T.; Takeda, N.; Sato, H.; the Norovirus Surveillance Group of Japan. Divergent evolution of norovirus GII/4 by genome recombination from May 2006 to February 2009 in Japan. J. Virol. 2010, 84, 8085-8097. 
21. Bailey, D.; Thackray, L.B.; Goodfellow, I.G. A single amino acid substitution in the murine norovirus capsid protein is sufficient for attenuation in vivo. J. Virol. 2008, 82, 7725-7728.

22. Bruggink, L.; Marshall, J. Molecular changes in the norovirus polymerase gene and their association with incidence of GII.4 norovirus-associated gastroenteritis outbreaks in Victoria, Australia, 2001-2005. Arch. Virol. 2008, 153, 729-732.

23. Bruggink, L.D.; Marshall, J.A. Identification of a novel codon in the norovirus GII.4 polymerase region which acts as a marker of major GII.4 norovirus epidemics. Infect. Genet. Evol. 2009, 9, 653-655.

24. Bull, R.A.; Eden, J.S.; Rawlinson, W.D.; White, P.A. Rapid evolution of pandemic noroviruses of the GII.4 lineage. PLoS Pathogens 2010, 6, e1000831.

25. Bull, R.A.; Tu, E.T.V.; McIver, C.J.; Rawlinson, W.D.; White, P.A. Emergence of a new norovirus genotype II.4 variant associated with global outbreaks of gastroenteritis. J. Clin. Microbiol. 2006, 44, 327-333.

26. Gallimore, C.I.; Iturriza-Gomara, M.; Xerry, J.; Adigwe, J.; Gray, J.J. Inter-seasonal diversity of norovirus genotypes: Emergence and selection of virus variants. Arch. Virol. 2007, 152, 1295-1303.

27. Siebenga, J.; Kroneman, A.; Vennema, H.; Duizer, E.; Koopmans, M. Food-borne viruses in Europe network report: the norovirus GII.4 2006b (for US named Minerva-like, for Japan Kobe034-like, for UK v6) variant now dominant in early seasonal surveillance. Euro. Surveill. 2008, 13, pii=8009.

28. Kroneman, A.; Vennema, H.; van Duijnhoven, Y.; Duizer, E.; Koopmans, M. High number of norovirus outbreaks associated with a GGII.4 variant in the Netherlands and elsewhere: Does this herald a worldwide increase? Euro. Surveill. 2004, 8, pii=2606.

29. Ho, E.C.M.; Cheng, P.K.C.; Lau, A.W.L.; Wong, A.H.; Lim, W.W.L. Atypical norovirus epidemic in Hong Kong during summer of 2006 caused by a new genogroup II/4 variant. J. Clin. Microbiol. 2007, 45, 2205-2211.

30. Oliver, B.; Ng, S.; Marshall, J.; Greenberg, H.; Gust, I.D.; Cresswell, V.; Ward, B.; Kennett, M.; Birch, C. Prolonged outbreak of Norwalk gastroenteritis in an isolated guest house. Med. J. Aust. 1985, 142, 391-395.

31. Marks, P.J.; Vipond, I.B.; Regan, F.M.; Wedgwood, K.; Fey, R.E.; Caul, E.O. A school outbreak of Norwalk-like virus: Evidence for airborne transmission. Epidemiol. Infect. 2003, 131, 727-736.

32. Marshall, J.A.; Dimitriadis, A.; Wright, P.J. Molecular and epidemiological features of norovirus-associated gastroenteritis outbreaks in Victoria, Australia in 2001. J. Med. Virol. 2005, 75, 321-331.

33. Bruggink, L.; Sameer, R.; Marshall, J. Molecular and epidemiological characteristics of norovirus associated with community-based sporadic gastroenteritis incidents and norovirus outbreaks in Victoria, Australia, 2002-2007. Intervirology 2010, 53, 167-172.

34. Parashar, U.D.; Dow, L.; Fankhauser, R.L.; Humphrey, C.D.; Miller, J.; Ando, T.; Williams, K.S.; Eddy, C.R,; Noel, J.S.; Ingram, T.; et al. An outbreak of viral gastroenteritis associated with consumption of sandwiches: Implications for the control of transmission by food handlers. Epidemiol. Infect. 1998, 121, 615-621. 
35. Marshall, J.A.; Salamone, S.; Yuen, L.; Catton, M.G.; Wright, P.J. High level excretion of Norwalk-like virus following resolution of clinical illness. Pathology 2001, 33, 50-52.

36. Goller, J.L.; Dimitriadis, A.; Tan, A.; Kelly, H.; Marshall, J.A. Long-term features of norovirus gastroenteritis in the elderly. J. Hosp. Infect. 2004, 58, 286-291.

37. Graham, D.Y.; Jiang, X.; Tanaka, T.; Opekun, A.R.; Madore, H.P.; Estes, M.K. Norwalk virus infection of volunteers: New insights based on improved assays. J. Infect. Dis. 1994, 170, 34-43.

38. Marshall, J.A.; Hellard, M.E.; Sinclair, M.I.; Fairley, C.K.; Cox, B.J.; Catton, M.G.; Kelly, H.; Wright, P.J. Failure to detect norovirus in a large group of asymptomatic individuals. Public Health 2004, 118, 230-233.

39. Garcia, C.; DuPont, H.L.; Long, K.Z.; Santos, J.I.; Ko, G. Asymptomatic norovirus infection in Mexican children. J. Clin. Microbiol. 2006, 44, 2997-3000.

40. Okabayashi, T.; Yokota, S.; Ohkoshi, Y.; Ohuchi, H.; Yoshida, Y.; Kikuchi, M.; Yano, K.; Fujii, N. Occurrence of norovirus infections unrelated to norovirus outbreaks in an asymptomatic food handler population. J. Clin. Microbiol. 2008, 46, 1985-1988.

41. Tu, E.T.V.; Bull, R.A.; Kim, M.J.; McIver, C.J.; Heron, L.; Rawlinson, W.D.; White, P.A. Norovirus excretion in an aged-care setting. J. Clin. Microbiol. 2008, 46, 2119-2121.

42. Gallimore, C.I.; Lewis, D.; Taylor, C.; Cant, A.; Gennery, A.; Gray, J.J. Chronic excretion of a norovirus in a child with cartilage hair hypoplasia (CHH). J. Clin. Virol. 2004, 30, 196-204.

43. Henke-Gendo, C.; Harste, G.; Juergens-Saathoff, B.; Mattner, F.; Deppe, H.; Heim, A. New real-time PCR detects prolonged norovirus excretion in highly immunosuppressed patients and children. J. Clin. Microbiol. 2009, 47, 2855-2862.

44. Westhoff, T.H.; Vergoulidou, M.; Loddenkemper, C.; Schwartz, S.; Hofmann, J.; Schneider, T.; Zidek, W.; van der Giet, M. Chronic norovirus infection in renal transplant recipients. Nephrol. Dial. Transplant. 2009, 24, 1051-1053.

45. Koopmans, M. Progress in understanding norovirus epidemiology. Curr. Opin. Infect. Dis. 2008, $21,544-552$.

46. Doultree, J.C.; Druce, J.D.; Birch, C.J.; Bowden, D.S.; Marshall, J.A. Inactivation of feline calicivirus, a Norwalk virus surrogate. J. Hosp. Infect. 1999, 41, 51-57.

47. Bae, J.; Schwab, K.J. Evaluation of murine norovirus, feline calicivirus, poliovirus, and MS2 as surrogates for human norovirus in a model of viral persistence in surface water and ground water. Appl. Environ. Microbiol. 2008, 74, 477-484.

48. Lamhoujeb, S.; Fliss, I.; Ngazoa, S.E.; Jean, J. Molecular study of the persistence of infectious human norovirus on food-contact surfaces. Food Environ. Virol. 2009, 1, 51-56.

49. Lay, M.K.; Atmar, R.L.; Guix, S.; Bharadwaj, U.; He, H.; Neill, F.H.; Sastry, K.J.; Yao, Q.; Estes, M.K. Norwalk virus does not replicate in human macrophages or dendritic cells derived from the peripheral blood of susceptible humans. Virology 2010, 406, 1-11.

50. Mounts, A.W.; Ando, T.; Koopmans, M.; Bresee, J.S.; Noel, J.; Glass, R.I. Cold weather seasonality of gastroenteritis associated with Norwalk-like viruses. J. Infect. Dis. 2000, 181 (Suppl 2), S284-S287.

51. Nygard, K.; Torven, M.; Ancker, C.; Knauth S.B.; Hedlund, K.O.; Giesecke, J.; Andersson, Y.; Svensson, L. Emerging genotype (GGIIb) of norovirus in drinking water, Sweden. Emerg. Infect. Dis. 2003, 9, 1548-1552. 
52. Hewitt, J.; Bell, D.; Simmons, G.C.; Rivera-Aban, M.; Wolf, S.; Greening, G.E. Gastroenteritis outbreak caused by waterborne norovirus at a New Zealand ski resort. Appl. Environ. Microbiol. 2007, 73, 7853-7857.

53. Bruggink, L.D.; Marshall, J.A. The incidence of norovirus-associated gastroenteritis outbreaks in Victoria, Australia (2002-2007) and their relationship with rainfall. Int. J. Environ. Res. Public Health 2010, 7, 2822-2827.

54. Wang, Q.H.; Han, M.G.; Cheetham, S.; Souza, M.; Funk, J.A.; Saif, L.J. Porcine noroviruses related to human noroviruses. Emerg. Infect. Dis. 2005, 11, 1874-1881.

55. Wolf, S.; Williamson, W.; Hewitt, J.; Lin, S.; Rivera-Aban, M.; Ball, A.; Scholes, P.; Savill, M.; Greening, G.E. Molecular detection of norovirus in sheep and pigs in New Zealand farms. Vet. Microbiol. 2009, 133, 184-189.

56. Wobus, C.E.; Thackray, L.B.; Virgin, H.W. Murine norovirus: A model system to study norovirus biology and pathogenesis. J. Virol. 2006, 80, 5104-5112.

57. Martella, V.; Lorusso, E.; Decaro, N.; Elia, G.; Radogna, A.; D’Abramo, M.; Desario, C.; Cavalli, A.; Corrente, M.; Camero, M.; Germinario, C.A.; Banyai, K.; Di Martino, B.; Marsilio, F.; Carmichael, L.E.; Buonavoglia, C. Detection and molecular characterization of a canine norovirus. Emerg. Infect. Dis. 2008, 14, 1306-1308.

58. Martella, V.; Decaro, N.; Lorusso, E.; Radogna, A.; Moschidou, P.; Amorisco, F.; Lucente, M.S.; Desario, C.; Mari, V.; Elia, G.; Banyai, K.; Carmichael, L.E.; Buonavoglia, C. Genetic heterogeneity and recombination in canine noroviruses. J. Virol. 2009, 83, 11391-11396.

59. Mesquita, J.R.; Barclay, L.; Nascimento, M.S.J.; Vinje, J. Novel norovirus in dogs with diarrhea. Emerg. Infect. Dis. 2010, 16, 980-982.

60. Ntafis, V.; Xylouri, E.; Radogna, A.; Buonavoglia, C.; Martella, V. Outbreak of canine norovirus infection in young dogs. J. Clin. Microbiol. 2010, 48, 2605-2608.

61. Martella, V.; Campolo, M.; Lorusso, E.; Cavicchio, P.; Camero, M.; Bellacicco, A.L.; Decaro, N.; Elia, G.; Greco, G.; Corrente, M.; Desario, C.; Arista, S.; Banyai, K.; Koopmans, M.; Buonavoglia, C. Norovirus in captive lion cub (Panthera leo). Emerg. Infect. Dis. 2007, 13, 1071-1073.

62. Mattison, K.; Shukla, A.; Cook, A.; Pollari, F.; Friendship, R.; Kelton, D.; Bidawid, S.; Farber, J.M. Human noroviruses in swine and cattle. Emerg. Infect. Dis. 2007, 13, 1184-1188.

(C) 2011 by the authors; licensee MDPI, Basel, Switzerland. This article is an open access article distributed under the terms and conditions of the Creative Commons Attribution license (http://creativecommons.org/licenses/by/3.0/). 